\title{
ANALISIS KEBUTUHAN AIR BERSIH DI KECAMATAN SELAT NASIK KABUPATEN BELITUNG PROVINSI BANGKA BELITUNG TAHUN 2017
}

\author{
Ika Kusumawati \\ Program Studi Teknik Lingkungan \\ Fakultas Teknik, Universitas Presiden \\ Jl. Ki Hajar Dewantara, Jababeka Education Park, Cikarang, Jawa Barat 17550 \\ 1k4kusmawati@gmail.com
}

\begin{abstract}
Abstrak: Kecamatan Selat Nasik merupakan salah satu kecamatan di Kabupaten Belitung yang berada di Pulau Selat Nasik yang memiliki persediaan air bersih terbatas. Hal ini dikarenakan lokasi dari kecamatan yang berada di wilayah kepulauan yang minim dalam mendapatkan sumber air bersih. Tujuan dari penelitian ini adalah untuk mengetahui potensi air bersih yang ada tersedia. Analisis yang digunakan dalam penelitian ini yaitu : analisis kebutuhan air bersih, analisis proyeksi penduduk, dan analisis ketersediaan air. Hasil dari menunjukkan bahwa ketersediaan air bersih pada tahun 2018 sebesar 466.366 liter/orang/hari dan pada tahun 2023 sebesar 519.611 liter/orang/hari. Sedangkan kebutuhan air bersih pada tahun 2018 sebesar 586.260 liter/orang/hari, pada tahun 2023 sebesar 556.470 liter/orang/hari. Dengan kata lain, kebutuhan air bersih di Kecamatan Selat Nasik hingga tahun 2023 belum dapat memenuhi kebutuhan air bersih bagi penduduknya.
\end{abstract}

Kata Kunci : Ketersediaan Air Bersih, Kebutuhan Air Bersih, Pertambahan Penduduk

\begin{abstract}
Kecamatan Selat Nasik is one of the subdistricts in Belitung Regency with limited avaliability of clean water. It is because the district located in the archipelago with limited clean water sources. The purpose of this study is to determine the potential of clean water. The analysis of this study are: clean water analysis, population growth analysis, and water availability analysis. The final result shows availability of clean water both 466.366 liter per person per day (in 2018) and 519.611 liter per person per day (in 2023). While the necessity of clean water required both 586.260 liter per person per day (in 2018) and 556.470 liter per person per day (in 2023). In other words, the needs of clean water in Kecamatan Nasik until 2023 can not been able to cover necessity of clean water population yet.
\end{abstract}

Keywords: Availability of clean water, necessity of clean water, population growth

\section{PENDAHULUAN}

Air merupakan sumber daya manusia yang sangat strategis dalam mendukung pertumbuhan ekonomi dan kesejahteraan masyarakat. Air merupakan bahan alam yang diperlukan untuk kehidupan manusia, hewan dan tanaman yaitu sebagai media pengangkutan zat-zat makanan, juga merupakan sumber energi serta berbagai keperluan lainnya (Arsyad, 1989). Sumber air dibedakan menjadi dua, air permukaan dan air tanah. Air permukaan seperti sungai, mata air dan rawa, rawan tercemar dengan berbagai polutan dan persediaannya pun tidak mencukupi di daerah pesisir. Sedangkan air tanah lebih terlindung dari berbagai pencemar, karena sumbernya berada di dalam lapisan tanah.
Pada tahun 2019 diperkirakan ada 60\% penduduk di Kecamatan Selat Nasik sulit untuk mendapat akses air bersih dikarenakan kualitas air yang payau/ tidak layak digunakan. Meski ini masih berupa persentasi perkiraan, paling tidak pemerintah harus memberikan perhatian serius pada persoalan air bersih. Menurut Suripin (2002), pada tahun 2000 dengan jumlah penduduk dunia sebesar 6,121 milyar diperlukan air bersih sebanyak 367 $\mathrm{km}^{3}$ per hari, maka pada tahun 2025 diperlukan air bersih sebanyak $492 \mathrm{~km}^{3}$ per hari, dan pada tahun 2100 diperlukan air bersih sebanyak $611 \mathrm{~km}^{3}$ per hari. Hal ini terjadi pula di salah satu wilayah di Provinsi Bangka Belitung yaitu Kecamatan Selat Nasik. 
Kecamatan Selat Nasik merupakan salah satu daerah yang mempunyai potensi sumber daya laut, dan terletak di lokasi yang strategis baik dalam lingkup wilayah Kabupaten Belitung, Provinsi Bangka Belitung dan lingkup eksternal. Permasalahan kebutuhan air bersih merupakan salah satu yang penting dalam pemenuhan kebutuhan penduduk seharihari, terutama pada saat musim kemarau. Berdasarkan kasus tersebut di atas, ada beberapa hal menarik untuk dikaji. Pertama mayoritas penduduk masih menggunakan sumber air minum yang rentan terhadap pencemaran, sementara sumber air minum yang yang aman dan mempunyai potensi besar untuk dimanfaatkan belum digunakan secara maksimal. Kedua, kawasan perdesaan di daerah pesisir, pada beberapa lokasi sudah terkena intrusi air laut. Oleh sebab itu, perlu solusi penyediaan air bersih untuk memenuhi kebutuhan penduduk. Sumber air bersih di daerah pesisir hanya berasal dari air hujan, air sungai dan air tanah dangkal (sumur). Air hujan jumlahnya fluktuatif serta memerlukan bak penampungan yang besar. Penggunaan air hujan hanya sebatas air minum, sementara untuk air bersih masih belum mencukupi secara kuantitas. Air sungai rentan terhadap pencemaran air asin. Sedangkan air tanah dalam hingga saat ini belum pernah diteliti potensi pemanfaatannya.

\section{BAHAN DAN METODE}

Kecamatan Selat Nasik dengan ibukota kecamatan berkedudukan di Desa Selat Nasik, memiliki luas wilayah $133,500 \mathrm{~km}^{2}$ atau $5,82 \%$ dari luas keseluruhan Kabupaten Belitung, terdiri atas 26 pulau dan terbagi atas 4 Desa/Kelurahan. Kecamatan ini dihuni oleh 1.458 rumah tangga dengan jumlah penduduk sebanyak 7.243 jiwa (kepadatan penduduk 54,255 jiwa $/ \mathrm{km}^{2}$ ). Keadaan tanah pada umumnya didominasi oleh kwarsa dan pasir, serta batuan granit. (Gambar 1)

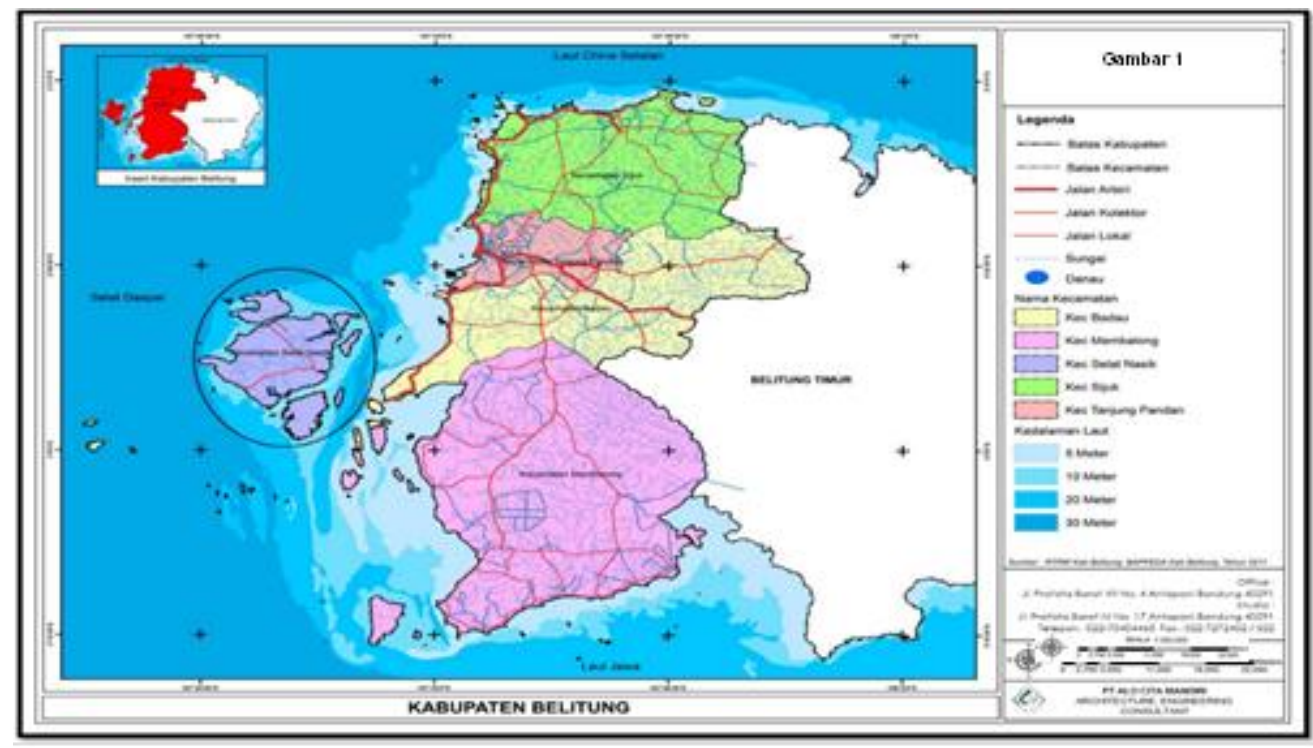

Gambar 1. Kecamatan Selat Nasik Kabupaten Belitung

\section{Metode Pengumpulan Data}

Pengumpulan data dalam penelitian ini dilakukan dengan mengumpulkan data primer dan studi pustaka. Pertama pengumpulan data primer ini dilakukan melalui metode observasi langsung ke lapangan. Kedua studi pustaka yaitu dengan mengumpulkan data-data yang diperlukan dari instansi yang ada di desadesa dan Kecamatan Selat Nasik, serta Kabupaten Belitung. Adapun data yang diperlukan antara lain data jumlah penduduk, potensi air bersih eksisting secara alami (air tanah maupun air permukaan), dan pola pemanfaatan air bersih yang ada. 


\section{Metode Analisis}

Dalam penelitian ini digunakan beberapa metoda analisis, yaitu :

\section{A. Analisis Proyeksi Penduduk}

Laju Pertumbuhan Penduduk Eksponensial digunakan dalam analisis ini untuk memprediksi jumlah penduduk suatu wilayah pada tahun 2018 dan 2023, dengan rumus:

$$
\begin{aligned}
& \mathrm{P}_{\mathrm{t}}=P_{0} \cdot e^{r t} \ldots \ldots \ldots \ldots \text { persamaan } 1 \\
& \text { dengan } \\
& \mathrm{r}=\frac{1}{t} \ln \left(\frac{P_{t}}{P_{0}}\right) \ldots \ldots \ldots \ldots \text { persamaan } 2
\end{aligned}
$$

Keterangan:

$\mathrm{Pt}=$ Jumlah penduduk pada tahun ke-t Po $=$ Jumlah penduduk pada tahun dasar

$\mathrm{t}=$ jangka waktu

$\mathrm{r}=$ laju pertumbuhan penduduk $\mathrm{e}=2,71$

\section{B. Analisis Ketersediaan Air}

\section{Analisa data curah hujan}

Dengan mengetahui tabel curah hujan di lokasi proyek atau di daerah sekitarnya yang diperoleh dari Badan Meteorologi Dan Geofisika setempat, maka kita dapat menggunakannya untuk kepentingan pekerjaan perencanaan teknis.

Data-data curah hujan yang diperoleh pada suatu lokasi proyek kadang kala tidak lengkap, berasal lebih dari satu stasiun pengamat hujan dan bahkan tidak ada sama sekali. Untuk itu perlu dilakukan analisis agar data yang digunakan mewakili karakteristik daerah proyek yang bersangkutan. Untuk lebih jelasnya dapat dilihat gambar dibawah ini yang menerangkan pengolahan data hujan menjadi hujan wilayah.

\section{Hujan Bulanan}

Data hujan bulanan di wilayah proyek bersumber dari BMG. Jika terdapat data hujan yang hilang, maka perlu dilakukan pengisian data hujan yang hilang berdasarkan data pos hujan yang terdekat.
Untuk keperluan pengisian data hujan, digunakan metode Normal Ratio Method:

$$
P_{x}=\frac{N_{x}}{M}\left(\sum_{i=1}^{M} \frac{P_{i}}{N_{i}}\right) \ldots \text { persamaan } 3
$$

$$
\begin{aligned}
& \text { Dimana : } \\
& \mathrm{Px}=\text { estimasi data hujan yang } \\
& \text { hilang di pos } \mathrm{x} \\
& \mathrm{Nx}=\text { curah hujan tahunan selama } \\
& \text { periode tertentu pada pos } \mathrm{x} \\
& \mathrm{M}=\text { jumlah pos hujan yang } \\
& \text { terdekat } \\
& \mathrm{Pi}=\text { data pos hujan tetangga } \\
& \text { pada bulan tertentu } \\
& \mathrm{Ni}=\text { curah hujan tahunan. }
\end{aligned}
$$

\section{HASIL DAN PEMBAHASAN Analisis Penduduk}

Berdasarkan data penduduk Kecamatan Selat Nasik pada tahun 2010 sampai dengan tahun 2015 yang diperoleh dari Badan Pusat Statistik Kabupaten Belitung, Kecamatan Selat Nasik terdiri dari 4 (empat) desa. Dari desa-desa yang ada, diproyeksikan pada tahun 2018 dan 2023. Hasil analisis proyeksi penduduk yang tertinggi berada di Desa Selat Nasik, yaitu: 2.481 jiwa (2018) dan 2.517 jiwa (2023). Sedangkan yang terendah di Desa Petaling yaitu: 2.481 jiwa (2018) dan 2.517 jiwa (2023). (Tabel 1 dan Gambar 2). Pertambahan jumlah penduduk yang semakin meningkat dapat kebutuhan air yang diperlukan di masa yang akan datang (Halim, dkk., 2013).

Perubahan jumlah penduduk di suatu wilayah tertentu pada waktu tertentu di bandingkan dengan waktu sebelumnya. (Afrianto, dkk., 2010). Kebutuhan air domestik adalah kebutuhan air yang dapat dihitung berdasarkan jumlah penduduk yang ada di daerah tersebut. Faktor utama yang menentukan adalah pertumbuhan penduduk (Zulkipli, dkk., 2011). Dalam kebutuhan air domestik hal yang paling berpengaruh dalam kebutuhan air adalah laju pertumbuhan penduduk (Kodoatie dan Sjarief, 2008). 
Tabel 1. Proyeksi Penduduk Kecamatan Selat Nasik Tahun 2018 - 2023

\begin{tabular}{|c|l|r|r|}
\hline \multirow{2}{*}{ No } & \multirow{2}{*}{ Desa } & \multicolumn{2}{|c|}{ Jumlah Penduduk(Jiwa) } \\
\cline { 3 - 4 } & & $\mathbf{2 0 1 8}$ & \multicolumn{2}{|c|}{$\mathbf{2 0 2 3}$} \\
\hline 1 & Suak Bual & 863 & 842 \\
\hline 2 & Petaling & 577 & 637 \\
\hline 3 & Selat Nasik & 2.481 & 2.517 \\
\hline 4 & Pulau Gersik & 2.393 & 2.187 \\
\hline \multicolumn{2}{|c|}{ Jumlah } & $\mathbf{6 . 3 0 5}$ & $\mathbf{6 . 1 4 0}$ \\
\hline
\end{tabular}

Sumber: Hasil Analisis, 2017

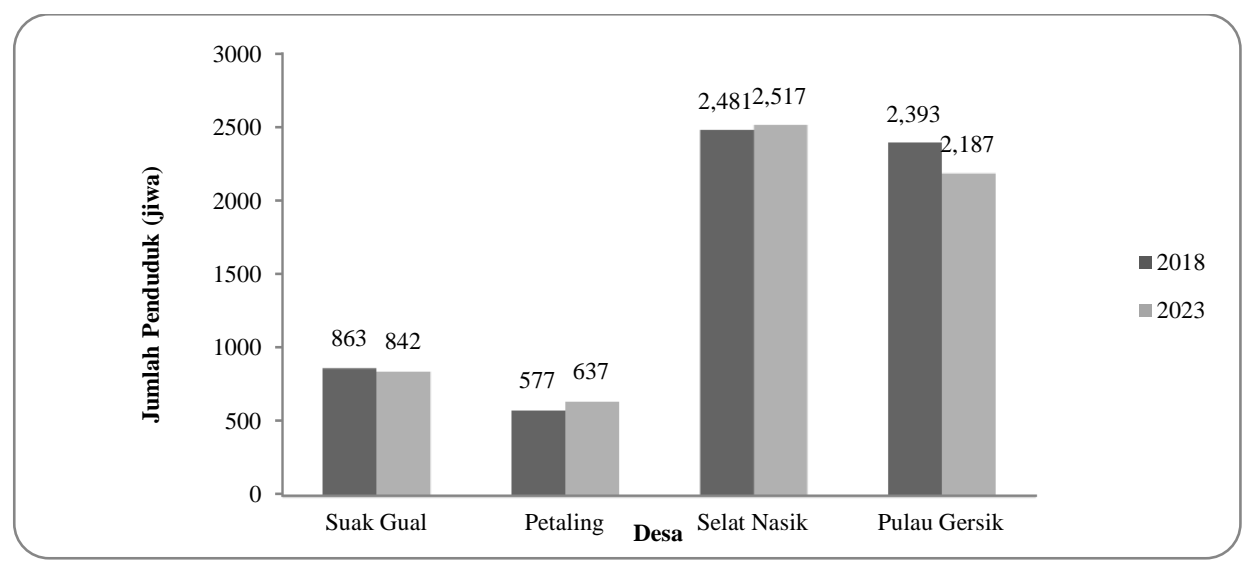

Gambar 2. Proyeksi Penduduk Kecamatan Selat Nasik Tahun 2018 - 2023 Sumber: Hasil Analisis, 2017

Analisis Ketersediaan dan Kebutuhan Air Bersih di Kecamatan Selat Nasik pada Tahun 2018 dan 2013

Kecamatan Selat Nasik memiliki karakteristik dan ciri khas tersendiri dibandingkan kecamatan yang lain di Kabupaten Belitung. Kecamatan Selat Nasik memiliki 4 desa yang tersebar di semua penjuru pulau dan terpisah jauh antara satu dengan yang lainnya. Ibukota Kecamatan berada di Desa Selat Nasik. Saat ini belum terdapat instalasi air bersih di Kecamatan Selat Nasik. Mayoritas penduduk menggunakan air sumur dangkal untuk memenuhi kebutuhan air bersih sehari - hari.

Potensi Air Permukaan di Kecamatan Selat Nasik diantaranya adalah:

Desa Selat Nasik. Terdapat sumber air bersih yang dapat dimanfaatkan di Desa Selat Nasik sebagai Ibukota Kecamatan di Desa Selat Nasik. Kapasitas tamping kolong Selat Nasik diperkirakan sekitar $15.000 \mathrm{~m}^{3}$. Kapasitas sebesar ini cukup untuk dipergunakan sebagai sumber air bersih penduduk Desa Selat Nasik sebanyak $300 \mathrm{KK}$.
Desa Petaling. Desa Petaling bisa dikatakan tidak memiliki sumber air bersih potensial yang bisa dimanfaatkan. Dari survey lapangan hanya diperoleh 1 buah sumber berjarak sekitar 500 meter dari desa, berupa aliran sungai kecil dengan kapasitas 1 liter / detik yang selama ini dimanfaatkan sebagai sumber air mobil tangki. Akan tetapi, untuk mencukupi kebutuhan desa secara keseluruhan sumber air ini tidaklah memadai.

Desa Suak Bual. Desa Suak Bual memiliki karakteristik sedikit berbeda dengan desa - desa lainnya di Kecamatan Selat Nasik. Desa ini memiliki kemiringan yang lebih tajam dan berada di pinggiran pantai. Litologi batuan Desa Suak Bual berupa gamping klastik yang tersebar di seluruh desa. Dengan kemiringan yang ekstrim menyebabkan tidak adanya potensi air permukaan di desa ini. Dimana air permukaan yang bersumber dari air hujan akan menjadi larian (run off) dan langsung kelaut. Pemenuhan kebutuhan air bersih saat ini hanya bersumber dari sumur gali dan beberapa sumur pantek dengan kedalaman 20 meter. 
Desa Gersik. Desa Gersik berpusat di Pulau Gersik dan terpisah dari Pulau Mendanau yang merupakan pulau utama dan sebagai Ibukota Kecamatan Selat Nasik. Desa Gersik sendiri tidak memiliki potensi sumber air permukaan. Sumber air yang ada dan selama ini menjadi tumpuan sumber air bagi masyarakat adalah sumur dangkal.

Secara umum Kecamatan Selat Nasik tersusun oleh 3 satuan formasi geologi yaitu Endapan Alluvial dan Pantai (Qa), Formasi Kelapa Kampit (PCks), dan Formasi Tajam (PCTm). Endapat Alluvial dan Pantai (Qa) tersusun dari endapan batuan lepas berupa kerakal, kerikil, pasir, lanau, lempung dan pecahan koral. Formasi Kelapa Kampit (PCks) tersusun oleh batuan sedimen yang telah terlipat lemah hingga sedang, yang terdiri dari batu pasir berselingan dengan batu sabak, batu lempung, serpih, lanau dan sabak. Formasi Tajam (PCTm) terdiri dari baru pasir kuarsa yang terlipatkan sedang hingga kuat dan termetamorfosa tingkat rendah. Formasi ini menjari dengan formasi kelapa kampit. Untuk lebih jelasnya dapat dilihat pada peta geologi kecamatan Selat Nasik berikut:

Berdasarkan aspek hidrogeologi, Kecamatan Selat Nasik memiliki potensi air tanah kecil hingga sedang. Desa Selat Nasik, Desa Suak Bual, dan Desa Gersik termasuk dalam wilayah air tanah langka dan harus mengandalkan sumber air tanah permukaan ataupun sumur dangkal. Sedangkan Desa Petaling termasuk dalam daerah dengan potensi air tanah sedang.
Seiring dengan sedikitnya potensi air permukaan Desa Petaling, air tanah dalam dapat menjadi salah satu pilihan yaitu dengan menggunakan sumur air tanah dalam sebagai sumber air bersih.

Berdasarkan Peraturan Pemerintah Republik Indonesia No 16 Tahun 2005 bahwa yang dimaksud dengan air baku untuk air minum rumah tangga, yang selanjutnya disebut air baku adalah air yang berasal dari sumber air permukaan (Joko, T 2010, hlm 53). Oleh karena itu proyeksi kebutuhan air bersih Kecamatan Selat Nasik sangat penting. Setelah dilakukan pengambilan data resistivitas untuk mengetahui ketersediaan air tanah dan potensinya untuk digunakan sebagai sumber air bersih, diperoleh data hasil analisis pada masing-masing desa di Kecamatan Selat Nasik adalah 466.366 liter/orang/hari (tahun 2018) dan 519.611 liter/orang/hari (tahun 2023).

Standar kebutuhan menggunakan acuan Peraturan Menteri Pekerjaan Umum Nomor 14/PRT/M/2010 tentang Standar Pelayanan Minimal Bidang Pekerjaan Umum dan Penataan Ruang yaitu 90 liter/orang/hari. Berdasarkan perhitungan dapat diketahui bahwa proyeksi kebutuhan air bersih di Kecamatan Selat Nasik pada tahun 2018 sebesar 586.260 liter/orang/hari, pada tahun 2023 sebesar 556.470 liter/orang/hari. Hal ini menunjukkan bahwa kebutuhan air bersih yang ada di Kecamatan Selat Nasik akan terus meningkat seiring dengan pertambahan jumlah penduduknya (Tabel 2 dan Gambar 3 dan Gambar 4)

Tabel 2. Proyeksi Ketersediaan dan Kebutuhan Air Bersih Kecamatan Selat Nasik Pada Tahun 2018 dan 2023

\begin{tabular}{|c|l|r|r|r|r|}
\hline \multirow{2}{*}{ No } & \multirow{2}{*}{ Desa } & \multicolumn{2}{c|}{$\begin{array}{c}\text { Ketersediaan Air } \\
\text { (liter/hari/orang)* }\end{array}$} & \multicolumn{2}{c|}{$\begin{array}{c}\text { Kebutuhan Air (liter/ } \\
\text { orang/hari)* }\end{array}$} \\
\cline { 3 - 6 } & & $\mathbf{2 0 1 8}$ & $\mathbf{2 0 2 3}$ & $\mathbf{2 0 1 8}$ & \multicolumn{1}{|c|}{$\mathbf{2 0 2 3}$} \\
\hline 1 & Suak Bual & 69.903 & 72.749 & 77.670 & 75.780 \\
\hline 2 & Petaling & 41.544 & 56.183 & 51.930 & 57.330 \\
\hline 3 & Selat Nasik & 169.700 & 217.469 & 223.290 & 226.530 \\
\hline 4 & Pulau Gersik & 185.218 & 173.210 & 215.370 & 196.830 \\
\hline & Jumlah & $\mathbf{4 6 6 . 3 6 6}$ & $\mathbf{5 1 9 . 6 1 1}$ & $\mathbf{5 6 8 . 2 6 0}$ & $\mathbf{5 5 6 . 4 7 0}$ \\
\hline
\end{tabular}

Sumber: Hasil Analisis, 2017

* Standar kebutuhan menggunakan acuan dari Ditjen Cipta Karya yaitu 90 liter/orang/hari 


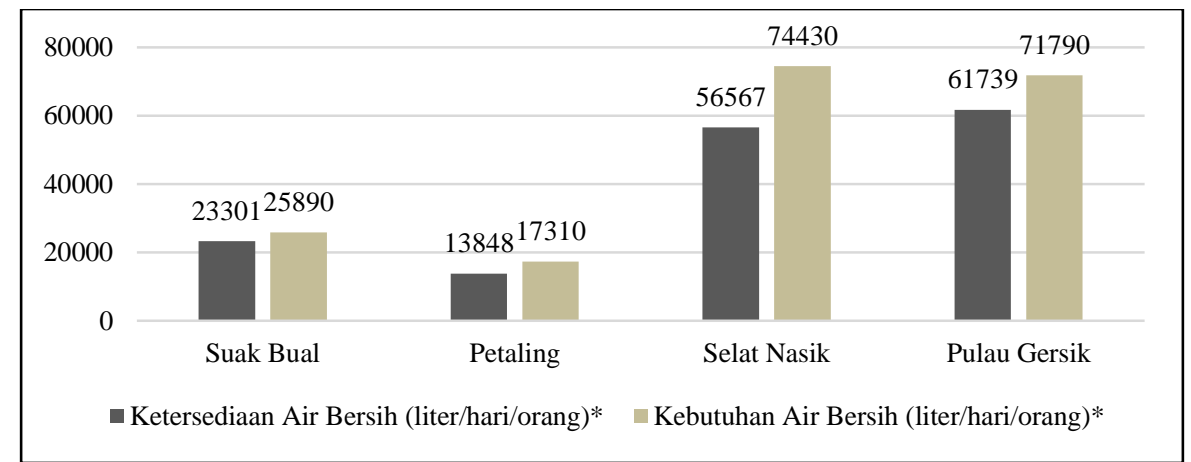

Gambar 3. Proyeksi Ketersediaan dan Kebutuhan Air Bersih Kecamatan Selat Nasik Pada Tahun 2018

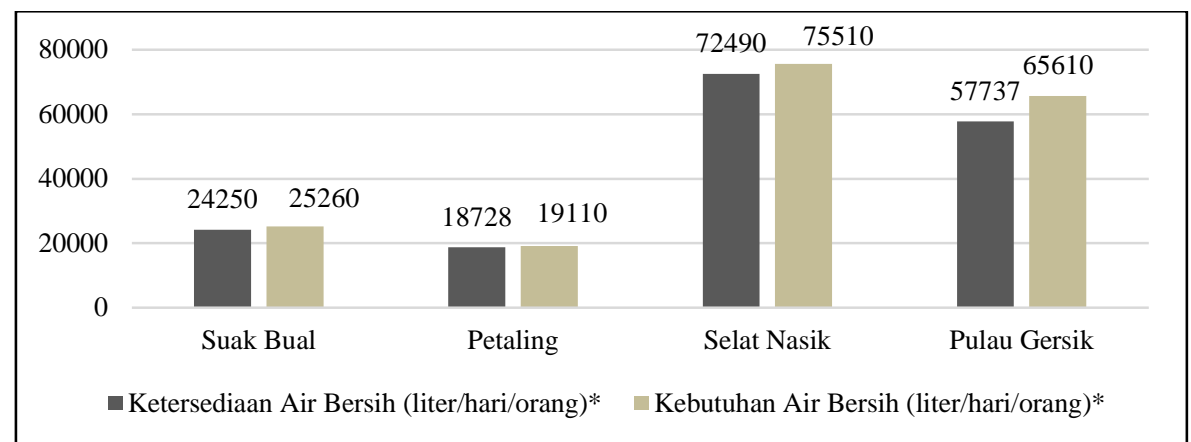

Gambar 4. Proyeksi Ketersediaan dan Kebutuhan Air Bersih Kecamatan Selat Nasik Pada Tahun 2023

\section{KESIMPULAN}

Ketersediaan air bersih di Kecamatan Selat Nasik merupakan salah satu kebutuhan yang penting bagi penduduk setempat. Dengan lokasi yang berada di daerah pesisir, penduduk menggunakan air yang berasal dari air hujan, air sungai dan air tanah dangkal (sumur). Kebutuhan air bersih di Kecamatan Selat Nasik terus meningkat seiring dengan pertambahan jumlah penduduknya. Untuk itu, perlu adanya upaya pemenuhan kebutuhan air bersih dari berbagai pihak, karena kebutuhan air bersih di Kecamatan Selat Nasik, tidak memenuhi/ tidak memadai kebutuhan air bersih penduduk.

\section{DAFTAR PUSTAKA}

Arsyad, S. 1989. Konservasi Tanah dan Air. IPB Press. Bogor.

Badan Pusat Statistik Kabupaten Belitung Tahun 2010-2015

Halim, F., Jasin, M. I., Kawet, L., et al. (2013). Pengembangan Sistem Pentediaan Air Bersih. Sipil Statik, Vol 1. Hlm: 444.
Joko, T. (2010). Unit air baku dalam sistem penyediaan air minum. Yogyakarta: Graha Ilmu.

Kodoatie-J, R. dan Sjarief. (2008). Pengelolaan sumber daya air terpadu. Yogyakarta: Andi.

Lukman Afrianto, Dede Rohmat., et al (1989). Konservasi Tanah dan Air. IPB Press. Bogor.

Peraturan Pemerintah Republik Indonesia No 16 Tahun 2005 Tentang. Pengembangan Sistem Penyediaan. Air Minum

Peraturan Menteri Pekerjaan Umum Nomor 14/PRT/M/2010 tentang Standar Pelayanan Minimal Bidang Pekerjaan Umum dan Penataan Ruang.Suripin. 2002. Pelestarian Sumberdaya Tanah dan Air. ANDI. Yogyakarta.

Zulkipli., Soetopo, W., Prasetijo, H., et al. (2012) Analisa Neraca Air Permukaan DAS Renggung Untuk Memenuhi Kebutuhan Air Irigasi Dan Domestik Penduduk Kabupaten Lombok Tengah. Teknik Pengairan, Vol 3. Hlm 89. 